ORIGINAL ARTCLE

\title{
Health Economic Evaluation of Home and Hospital-Based Care in T2D Patients on Insulin Therapy
}

\author{
Ali Janati ${ }^{1}$, Mohamad Ali Sarabchian ${ }^{2}$, Bahram Mohaghegh ${ }^{3^{*}}$, \\ NaserAghmohamadzadeh ${ }^{2}$, Hesam Seyedin ${ }^{4}$, Masumeh Gholizadeh ${ }^{1}$, Edris \\ Hasanpoor $^{1}$
}

\footnotetext{
OPEN ACCESS

Citation: Ali Janati, Mohamad Ali Sarabchian, BahramMohaghegh, NaserAghmohamadzadeh, Hesam Seyedin, Masumeh Gholizadeh, Edris Hasanpoor. Health Economic Evaluation of Home and Hospital Based Care in T2D Patients on Insulin Therapy. Ethiop J HealthSci.2017;27(6):651 doi:http://dx.doi.org/10.4314/ejhs.v27i6.1

Received: May 20, 2017

Accepted: May 26, 2017

Published: November 1, 2017

Copyright: () 2017 Ali Janati, et al. This is an open access article distributed under the terms of the Creative Commons Attribution License, which permits unrestricted use, distribution, and reproduction in any medium, provided the original author and source are credited.

Funding: Nil

Competing Interests: The authors declare that this manuscript was approved by all authors in its formand that no competing interest exists.

Affiliation and Correspondence:

${ }^{1}$ Iranian Center of Excellence in Health Management, School of Management and Medical Informatics, Tabriz University of Medical Sciences, Tabriz, Iran

${ }^{2}$ Department of Internal Medicine, Faculty of Medicine, Endocrinology Research Center, Clinical Sciences Institute, Tabriz University of Medical Sciences, Tabriz, Iran

${ }^{3}$ Department of Public Health, School of Health, Qom University of Medical Sciences, Qom, Iran

${ }^{4}$ Department of School of Health Management and Information Sciences, Iran University of Medical Sciences, Tehran, Iran

*Email: bmohaghegh@gmail.com
}

\section{ABSTRACT}

BACKGROUND: Type 2 Diabetes is a main concern of public health in contemporary world with remarkable mortality, delayed complications and health costs. Governments are obliged to improve the quality of health care and consider appropriate strategies to reduce the costs. An alternative strategy for hospital services is care at home. Therefore, this study was aimed to evaluate the cost-effectiveness of home-based and hospital-based diabetes care.

METHODS: A quasi-experimental, pre-test and post-test design was conducted in Northwest Iran. Sixty subjects who were eligible insulin-treatment type 2 diabetes mellitus were randomly assigned into two equal groups to receive home-based or conventional hospital-based care. Data on glycosylated hemoglobin (HbAlc), hypoglycemia episodes, time needed to achieve glycemic control level, diabetes treatment satisfaction, diabetes knowledge and costs during three months were collected.

RESULTS: The cost of home-based care in insulin therapy diabetes was $61 \%$ less compared with the hospital-based methods. The former strategy was cost-effective in terms of reduction in HbA1C and the time needed to achieve glycemic control. The patients in home care group were more satisfied and knowledgeable.

CONCLUSIONS: The care at home approach for type 2 diabetic patients can be introduced and supported as a cost-effective care method in the country.

KEYWORDS: Cost-effectiveness, type 2 diabetes, insulin therapy, home care, hospital care

\section{INTRODUCTION}

Type 2 Diabetes Mellitus (T2DM) is a globally rising chronic disease (1). This metabolic disorder causes serious damages to vital organs such as eyes, kidneys and nerves in the long term. Its complications are among the main causes of mortality and morbidity in the world. During 2005 to 2030, the diabetes-related deaths are projected to be doubled in theworld (2). The World Health Organization report in 
2014 shows that 347 million people in the world had diabetes of whom 4.581 million were living in Iran with a $8.6 \%$ prevalence (3).

This metabolic disease imposes a significant cost of $12 \%$ of the health expenditures (i.e. 1330 USD per person) in the world. It is $11 \%$ in Iran (4).

Diabetes as a chronic disease has no definite cure but providing good metabolic control could prevent or delay its complications (5). Thus, health systems and professionals should be prepared to detect and manage the disease and its sequelae. Also, a new role of home-based care is needed to be delegated to patients with chronic diseases management (6).

The demand for home health care has gined increasing currency in recent years. Aging population and the push for more efficient delivery of hospital services have fueled this growing demand. Therefore, an alternative strategy to expensive hospital-based care is home and community-based care because of their cost containment (7). As evidence is needed to provide information for efficiency and effectiveness of hospital or home-based care, this research was designed to compare these two strategies in terms of their cost effectiveness for control of type 2 diabetes mellitus.

In Iran, a national program for prevention and control of type 2 diabetes was designed in 1996 (8). The diabetes care was integrated in three levels of the Iranian health system. Early detection and treatment of diabetes are usually made at the first level (i.e. rural and urban health centers) by general physicians and allied health staff. All diabetic patients recognized in health centers are referred to district diabetes clinics located in general hospitals as the second level to early detection and control of complications. In these clinics, patients are visited by internists (or endocrinologist) and get care by nurses and nutritionist staff. Patients needing more specific treatments are referred to the diabetes centers foung in the provincial hospitals, which manage diabetes complications and provide educational support.

\section{MATERIAL AND METHODS}

Study Design: This research was a quasiexperimental, pre-test and post-test study conducted in 2013. The setting was a diabetes clinic in an Iranian teaching hospital. The study population were patients with type-2 diabetes getting care from a diabetes clinic in Tabriz, Iran. The subjects included diabetics who needed to change oral anti-diabetic therapy to insulin injection according to the internal specialists' orders. The diabetics with co-morbid conditions such as acute infections, thromboembolic diseases, getting glucocorticosteroids and recent surgery or trauma were excluded. The eligible subjects were randomly assigned into two equal groups to receive home-based or conventional hospital-based care.

The patients within the intervention group received home care and frequent follow-up of nurse visits and consultations at home. The control group patients received routine care, including inpatient services in hospital and subsequently monthly visits to the diabetes clinic. Figure 1 illustrates a flowchart of the two approaches in this study.

Sample size: To calculate the sample size, an estimate of the mean and variance of $\mathrm{HbA} 1 \mathrm{c}$ from a similar study was used (9). Therefore, the total sample size with the attrition rate of $20 \%$ was calculated to be 60 patients $(\mathrm{N}=60)$.

The measure: HbAlc was used to assess costeffectiveness of two employed strategies. It is an index of overall glycemic exposure and risk for long-term complications of diabetes mellitus (10). This test is performed to approximate metabolic control over the previous 2-3 months and to help treatment decisions (11).

A satisfaction measuring questionnaire with 20-items and five Likert scale was developed by researchers reviewing some diabetes treatment satisfaction tools $(12,13)$. The participants' knowledge relating to the insulin injection, selfmonitoring, hypoglycemia and complications was examined by employing a researcher-designed questionnaire with 15 closed-ended questions.

DOI: http://dx.doi.org/10.4314/ejhs.v27i6.10 
Three internists confirmed the validity of the questionnaire.

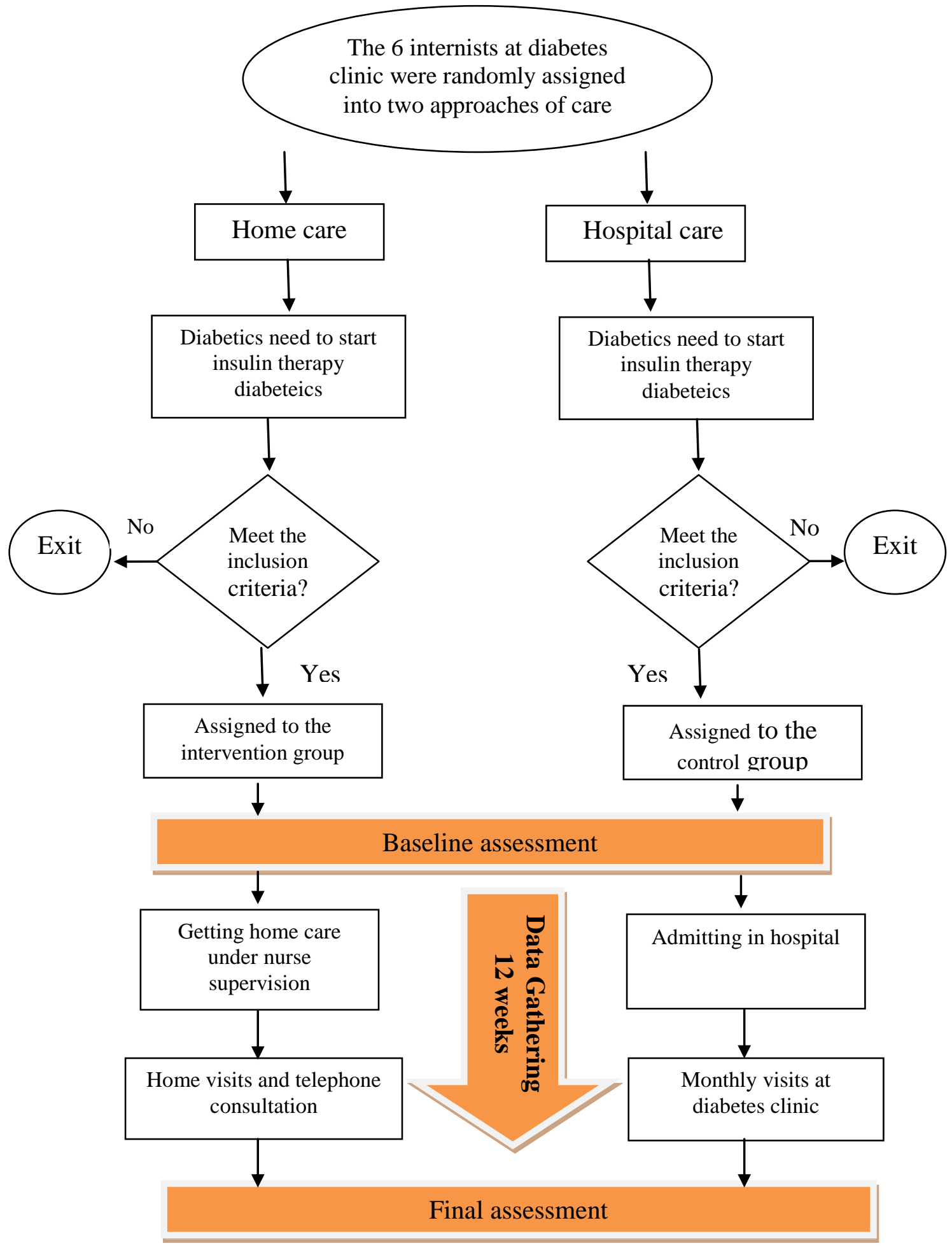

Figure1: the Flowchart of home and hospital care approaches

DOI: http://dx.doi.org/10.4314/ejhs.v27i6.10 
Besides, two process metrics, including hypoglycemia episodes and time needed to achieve the glycemic control were measured during a three-month period. The diagnosis of hypoglycemia was based on personal experience of patients with at least one physical symptom (e.g. shakiness and fast heartbeat) as well as psychological (e.g. anxiety) and neuroglycopenic (e.g. confusion) states. The index of the time needed to achieve the glycemic control was compared with the target level of blood glucose (FBG $=70-130 \mathrm{mg} / \mathrm{dl}$ or blood glucose 2 hours after meal $<180 \mathrm{mg} / \mathrm{dl}$ ).

The schedule of diabetes care: The patients in the home-based group received visits and consultations by a team consisting of nurses and endocrinologists. The intervention was focused on encouraging participants to engage in activities that protect and promote health such as modifying behavior, and change in diet, medication and blood glucose monitoring. The cases received three personal home-visits (first day of the experiment and two with monthly intervals) and ten follow-up phone calls (twice in the first week and eight at weeks $2,3,4,6,8,10$ and 12) provided by a nurse. Home visits and calls averaged 45 and 14 minutes each, respectively. Five telephone consultations led by medical specialists were performed per case.

The patients in the control group received regular services based on a conventional programme of diabetes control in Iran. They had insulin injection therapy in hospital, to control their glucose levels, and monthly physician appointment in diabetes clinics.

Data gathering: Data gathering was performed by a paper data sheet for recording the background characteristics (age, gender and the literacy level of subjects) and the indices showing the quality of diabetes care during the 3-month period of the study (the frequency of hypoglycemia episodes and time needed to achieve the glycemic control).

Two indexes including, HbAlc and patients' diabetes knowledge were measured twice at the beginning and end of the study (after three months). Also, patients' satisfaction was assessed with two approaches.
Individual table-sheets were used to register the direct costs of diabetes care for patients. The costs in the conventional approach included charges of outpatient care (i.e. physician visits, lab tests, medications and allied health care) and inpatient hospitalization. The costs calculated for the intervention group were the outpatient care, home visits, telephone consultations and endocrinologists consultations. The main nonmedical cost for both groups was the travel costs.

Statistical analysis: Descriptive statistics was used to summarize the characteristics of participants. Parametric and nonparametric tests were used according to Kolmogorov-Smirnov test for normality. Paired and independent t-tests were performed to verify the pre-post differences within the groups and differences between groups. We used the Mann-Whitney U or Wilcoxon test for data which were not normally distributed. Also, analysis of covariance (ANCOVA) was used to compare quantitative variables between the two groups when adjusting for another covariate was needed.

Ethical approval: Ethical approval was obtained from the Local Research Ethics Committee of the Tabriz University of Medical Sciences. A written informed consent was taken before randomization of subjects into home-based and hospital-based group. Informed consent was obtained from all individual participants for whom identifying information is included in this article.

\section{RESULTS}

Due to the attrition of five participants, data of 55 subjects were analyzed. The mean age of patients in the two groups of home-based and hospitalbased were $53.15 \pm 8.25$ and $58.41 \pm 13.68$, respectively. The ratio of males in home-based participants (15 of 26;58\%) and hospital-based group (10 out of $29 ; 34 \%)$ was not similar $(\mathrm{P}<0.05)$. Also, illiterate participants were more prevalent in hospital-based groups (69\% vs. 46\%) $(\mathrm{P}<0.05)$, but the mean weight in home-based group $(71.52 \pm 11.66 \mathrm{~kg})$ was not significantly different from hospital-based one $(71.41 \pm 13.68$ $\mathrm{kg})(\mathrm{P}<0.05)$. 
This study was also found that the mean $\mathrm{HbAlc}$ dropped significantly in the home-based group (paired t test: $\mathrm{t}=8.80, \mathrm{df}=23, \mathrm{P}<0.001$ ), but it did not change in the hospital-based group (paired $\mathrm{t}$ test: $\mathrm{t}=-0.72$, $\mathrm{df}=25, \mathrm{P}<0.47$ ). Also, the majority of the home-based patients experienced at least once hypoglycemia event whereas this experience was very rare in the alternative group $(53.8 \%$ vs. $3.4 \%) \quad(\mathrm{p}<0.001)$. More details regarding the diabetes knowledge, satisfaction level and time needed to achieve glycemic control could be found in Table 1.

Table 1: Comparing the characteristics between the two study groups.

\begin{tabular}{|c|c|c|c|}
\hline Variables & Home-based $(n=26)$ & Hospital-based $(n=29)$ & $P$-value \\
\hline Diabetes Knowledge & & & $<0.001$ \\
\hline Before & $45.38 \pm 12.65$ & $45.93 \pm 10.67$ & \\
\hline After & $83.07 \pm 10.19$ & $47.65 \pm 10.07$ & \\
\hline$P$-value & $<0.001^{\S}$ & $0.47^{\S}$ & \\
\hline Patient satisfaction score & $85.24 \pm 10.23$ & $68.20 \pm 13.29$ & $0.001 ¥$ \\
\hline The time needed to achieve glycemic control & $7(1)$ & $9(15)$ & $0.014^{\ddagger}$ \\
\hline
\end{tabular}

Table 2 indicates that the average costs for diabetes care in the three-month period were significantly difference between the intervention and control groups $(t=13.42 ; \mathrm{p}<0.001)$. It is worth mentioning that the strategy of home-based care was dominant over hospital-based care in terms of less cost to reduce a unit of $\mathrm{HbA} 1 \mathrm{c}$ in diabetic patients. This study also shows that to achieve prevention, an additional hypoglycemia in diabetics 106.93 US Dollar is needed. This cost needs to be compared with the Iranian threshold of cost-effectiveness values for diabetes management.

Table 2: Incremental Cost-effectiveness Ratios of different strategies among study groups

\begin{tabular}{|c|c|c|c|c|c|}
\hline Group & $\begin{array}{c}\text { Total cost (SD) } \\
\text { (USD)/per person }\end{array}$ & Outcome & $\begin{array}{c}\text { Incremental cost } \\
\text { (US \$) }\end{array}$ & $\begin{array}{l}\text { Incremental } \\
\text { effectiveness }\end{array}$ & ICER* \\
\hline \multicolumn{6}{|l|}{ HbA1c } \\
\hline Home-based & $45.88(7.54)$ & & - & - & Dominant \\
\hline Before & & $11.40(2.37)$ & & & \\
\hline After & & $7.30(1.42)$ & & & \\
\hline Hospital-based & $116.46(27.17)$ & & 70.58 & 4.13 & Dominated \\
\hline Before & & $10.58(1.80)$ & & & \\
\hline After & & $10.65(1.82)$ & & & \\
\hline \multicolumn{6}{|c|}{ Hypoglycemia episodes } \\
\hline Home-based & $45.88(7.54)$ & $14(53.8)$ & - & - & - \\
\hline Hospital-based & $116.46(27.17)$ & $1(3.4)$ & 70.58 & 0.66 & 106.93 \\
\hline \multicolumn{6}{|l|}{ Satisfaction score } \\
\hline Home-based & $45.88(7.54)$ & $85.24(10.23)$ & - & - & Dominant \\
\hline Hospital-based & $116.46(27.17)$ & $68.20(13.29)$ & 70.58 & 17.04 & Dominated \\
\hline \multicolumn{6}{|c|}{ Time needed to achieve glycemic control ** } \\
\hline Home-based & $45.88(7.54)$ & $7(1)$ & - & - & Dominant \\
\hline Hospital-based & $116.46(27.17)$ & $9(15)$ & 70.58 & 4.48 & Dominated \\
\hline $\begin{array}{l}\text { - Variables with } 1 \\
\text { - Variables with } 1 \\
\text { - Variables with } \\
\text { *Incremental Cost-e }\end{array}$ & $\begin{array}{l}\text { meric scales are report } \\
\text { al numeric scales are re } \\
1 \text { scales are reported as } \\
\text { ss Ratios }\end{array}$ & $\begin{array}{l}\text { as Mean (stand } \\
\text { orted as Median } \\
(\%) \text {. }\end{array}$ & $\begin{array}{l}\text { d deviation) } \\
\text { interquartile range (I }\end{array}$ & & \\
\hline
\end{tabular}

DOI: http://dx.doi.org/10.4314/ejhs.v27i6.10 


\section{DISCUSSION}

The findings showed that the mean costs of diabetes care could be reduced by $61 \%$ at homebased strategy. This finding, regardless of the different diseases being studied, was congruent with some studies $(12,13)$ and inconsistent with others (14), in terms of predominant cost-saving strategy.

Comparing the effects of home- and hospitalbased care revealed that the home-based method had more effect on improving clinical and nonclinical outcomes. The interventional cases experienced a mean of $37 \%$ reduction in their HbA1c levels (from 11.4 to 7.3) after three months. Such a finding came in agreement with several studies that reported a significant decrease in $\mathrm{HbA} 1 \mathrm{c}$ of diabetics getting a nurse-led home diabetes management program compared with the control group (15-18). This reduction in HbA1c level could result in reducing the development of severe complications in diabetics (19). It is suggested that nurse visits and telephone counseling in home-based strategy could develop individual self-management for diabetes control (20). In some forms of interventions that diabetes education and counseling or phone calls follow-up were made by nurses, different results were reported. For example, Gallegos et al. reported a significant decrease in $\mathrm{HbA} 1 \mathrm{c}$ in the experimental group (21), but with a nurse-coaching strategy undertaken by Whittemore et al. the HbAlc levels improved in both the control and the intervention groups (22).

It seems frequent medical staff contacts with patients in the home-based strategy, comparing with the usual strategy could positively affect HbA1c level (23). The central role of nurses as an impressive factor to improve health outcome in patients with chronic diseases has been reported by Sutherland et al. (24).

In this study, the diabetes knowledge and awareness of the intervention subjects was significantly improved. Consistent with findings of Zareban et al., the improvement was concurrent with falling in HbA1c levels (25). Comparing the mean time (in days) to achieve the optimum level of blood glucose in patients was statistically similar in the two groups; but, almost four and a half days shorter in the intervention than control group. The home-care strategy was dominant over the conventional strategy in terms of less cost, but more effect on reducing the time (days) needed to achieve the glycemic control in diabetics.

The tarticipants in the experimental group reported more hypoglycemic episode than the control group. This is in contrast with a study has been done by Piette et al. (26). These results should be taken with caution, since the use of a self-reporting approach for data collection constitutes a potential source of bias in the form of underestimating the true numbers of hypoglycemia episodes especially in usual care subjects due to lack of any scheduled supervision by health staff.

Finally, the participants in the experimental care demonstrated more satisfaction than the usual care which is inconsistent with a study done by Navicharern et al. (16). It can be concluded that home-based model of diabetes care generates better outcomes at lower costs than conventional care, that encourages integration of home health care into the usual program of diabetes prevention and control.

It seems that the home-based approach by reinforcing the team work through nurses' home visits and phone calls plus physicians' phone counseling has potentially positive effects on diabetes control in adults with insulin-treated diabetes type 2 that in turn could prevent or delay the complications. Further research is needed to clarify the optimum number of home visits and nurse or physician phone counseling needed to achieve the maximum outcomes in diabetics and to investigate the long term consequences of home care compared with the usual care.

The limitations of this study include the following issues:

- Patients who received the intervention had higher literacy levels at baseline than the control subjects. This would have resulted in an overestimation of the increased diabetes knowledge at the end of the study. 
- Due to limited resources, the time to follow the participants up was not continued after three months. Two measures of diabetes control estimates (i.e. time needed to achieve the glycemic control and hypoglycemic episodes) were based on self-reports, i.e., their direct measures by health staff were not available to validate data.

- The mean value of HbA1c level at baseline was almost similar among the experimental and the control groups, indicating the strength of the finding that the remarkable reduction of noted index in the home-care was true.

\section{REFERENCES}

1. Danaei G, Finucane MM, Lu Y, Singh GM, Cowan MJ, Paciorek CJ, et al. National, regional, and global trends in fasting plasma glucose and diabetes prevalence since 1980: systematic analysis of health examination surveys and epidemiological studies with 370 country-years and 2.7 million participants. The Lancet. 2011;378(9785):31-40.

2. World Health Organization. Diabetes mellitus Fact sheet 312. 2015 [cited 2016]; Available from: http://www.who.int/mediacentre/ factsheets/fs312/en/.

3. International Diabetes Federation. Middle East and North Africa. 2014; Available from: http://www.idf.org/membership/mena/iran.

4. Zhang $\mathrm{P}$, Zhang $\mathrm{X}$, Brown J, Vistisen D, Sicree R, Shaw J, Nichols G. Global healthcare expenditure on diabetes for 2010 and 2030. Diabetes Res Clin pract. 2010 Mar;87(3):293-301.

5. Alberti G. Tight glycaemic control: the key to improving the management of type 2 diabetes. The British Journal of Diabetes \& Vascular Disease. 2005;5(4):184-5.

6. Holman H, Lorig K. Patient selfmanagement: a key to effectiveness and efficiency in care of chronic disease. Public health Rep. 2004;119(3):239-43.

7. Andersson A, Levin LA, Öberg B, Månsson L. Health care and social welfare costs in home-based and hospital-based rehabilitation after stroke. Scand J Caring Sci. 2002 Dec;16(4):386-92.

8. Azizi F, Guoya M, Vazirian P, Dolatshati P, Habbibian S. Screening for type 2 diabetes in the Iranian national programme: a preliminary report. East Mediterr Health J. 2003 Sep-Nov; 9(5-6): 1122-7.

9. Bonakdaran S, Mojahedi M, Ayatollahi H, Shakery M. Effects of Calcitriol $(1,25(\mathrm{OH})$ 2D3 Treatment on Control of Glucose Intolerance in Hemodialysis Patients. Iranian Journal of Endocrinology and Metabolism. 2008;10(3):265-71.

10. International Expert Committee . International Expert Committee report on the role of the A1C assay in the diagnosis of diabetes. Diabetes care. 2009;32(7):1327-34.

11. World Health Organization. Diabetes programme. 2015; Available from: http://www.who.int/diabetes/action_online /basics /en/index1.html.

12. Cappelleri JC, Gerber RA, Kourides IA, Gelfand RA: Development and factor analysis of a questionnaire to measure patient satisfaction with injected and inhaled insulin for type I diabetes. Diabetes Care 23:1799$1803,2000$.

13. Anderson RT, Skovlund SE., Marrero D, Levine DW, Meadows K, Brod M, Balkrishnan R: Development and validation of the insulin treatment satisfaction questionnaire. Clin Ther 26:565-578, 2004.

14. Ho YL, Hsu TP, Chen CP, Lee CY, Lin YH, Hsu RB, et al. Improved cost-effectiveness for management of chronic heart failure by combined home-based intervention with clinical nursing specialists. JFormos Medl Assoc. 2007 Apr;106(4):313-9.

15. Moalosi G, Floyd K, Phatshwane J, Moeti T, Binkin N, Kenyon T. Cost-effectiveness of home-based care versus hospital care for chronically ill tuberculosis patients, Francistown, Botswana. The IntTuberc Lung Dis. 2003;7(9suppl1).

16. Taylor RS, Watt A, Dalal HM, Evans PH, Campbell JL, Read KL, et al. Home-based cardiac rehabilitation versus hospital-based 
rehabilitation: a cost effectiveness analysis. Int $j$ Cardiol. 2007 Jul 10;119(2):196-201.

17. Huang CL, Wu SC, Jeng CY, Lin LC. The Efficacy of a Home-Based Nursing Program in Diabetic Control of Elderly People with Diabetes Mellitus Living Alone. Public Health Nurs. 2004 Jan-Feb;21(1):49-56.

18. Navicharern R, Aungsuroch Y, Thanasilp S. Effects of multifaceted nurse-coaching intervention on diabetic complications and satisfaction of persons with type 2 diabetes. $J$ Med Assoc Thai. 2009 Aug;92(8):1102-

19. Song M-S, Kim H-S. Intensive management program to improve glycosylated hemoglobin levels and adherence to diet in patients with type 2 diabetes. Appl Nurs Res. 2009 Feb;22(1):42-7.

20. Spencer MS, Rosland A-M, Kieffer EC, Sinco BR, Valerio M, Palmisano G, et al. Effectiveness of a community health worker intervention among African American and Latino adults with type 2 diabetes: a randomized controlled trial. Am J Public Health. 2011 Dec;101(12):2253-60.

21. Nordwall M, Abrahamsson M, Dhir M, Fredrikson M, Ludvigsson J, Arnqvist HJ. Impact of $\mathrm{HbA1c}$, followed from onset of type 1 diabetes, on the development of severe retinopathy and nephropathy: the VISS Study (Vascular Diabetic Complications in Southeast Sweden). Diabetes care. 2015 Feb;38(2):308-15.

22. Kıtış Y, Emıroğlu ON. The effects of home monitoring by public health nurse on individuals' diabetes control. Appl Nurs Res. 2006;19(3):134-43.

23. Gallegos EC, Ovalle-Berúmen F, Gomez-Meza MV. Metabolic control of adults with type 2 diabetes mellitus through education and counseling. J Nurs Scholarsh. 2006;38(4):344-51.

24. Whittemore R, Melkus G, Sullivan A, Grey M. A nurse-coaching intervention for women with type 2 diabetes. Diabetes Educ. 2004 Sep-Oct;30(5):795-804.

25. Pimouguet $\mathrm{C}$, Le Goff $\mathrm{M}$, Thiébaut R, Dartigues JF, Helmer C. Effectiveness of disease-management programs for improving diabetes care: a meta-analysis. CMAJ. 2011;183(2):E115-E27.

26. Sutherland D, Hayter M. Structured review: evaluating the effectiveness of nurse case managers in improving health outcomes in three major chronic diseases. J Clin Nurs. 2009 Nov; 18(21):2978-92.

27. Zareban I, Niknami S, Hiedarnia AR, Rakhshani F, Sharakipour M, Moshki M. The effect of education based on health belief model on reduction of $\mathrm{HbA} 1 \mathrm{c}$ level in diabetes type 2. Journal of Research \& Health. 2013;3(2):370-8.

28. Piette JD, Weinberger M, McPhee SJ, Mah CA, Kraemer FB, Crapo LM. Do automated calls with nurse follow-up improve self-care and glycemic control among vulnerable patients with diabetes? Am J Med. 2000 Jan;108(1):20-7. 